\title{
Study of the Swelling of a Composite Based on Argan Nut, Urea-Formaldehyde and Water as a Non-Polluting Solvent
}

\author{
Fouad Babty $^{1 *}$, Abdelilah Hachim² ${ }^{2}$ M’barka Mourabit ${ }^{1}$, Soumia Mordane ${ }^{1}$, Amina Bettachy ${ }^{1}$, Abdeslam El Assyry ${ }^{1}$, \\ Abdelali Derouiche ${ }^{1}$ \\ ${ }^{1}$ Laboratory of Polymer Physics, Mechanical Sciences and Materials, Department of Physics, Faculty of Sciences Ben M'Sik, \\ Hassan II University of Casablanca, Casablanca 20670, Morocco \\ ${ }^{2}$ Higher Institute of Maritime Studies - Casablanca (ISEM) Km 7, Route El-Jadida, Casablanca 20100, Morocco
}

Corresponding Author Email: fouad.babty@gmail.com

https://doi.org/10.18280/rcma.310505

Received: 23 August 2021

Accepted: 15 October 2021

\section{Keywords:}

Argania spinosa, biomaterials, shells, swelling coefficient, urea-formaldehyde

\begin{abstract}
In the center and southwest of Morocco, there is an endemic tree «Argania Spinosa» known as the ironwood. The miraculous product of this millenary tree is argan oil. Known for its therapeutic and cosmetic properties. Only $20 \%$ of the fruit of the argan tree is intended for the manufacture of argan oil while the shell, which represents $80 \%$, remains an unexploited resource. This hull, which is sold by farmers at low prices, is used as fuel for baths and Moorish bakeries. In order to value the shells; first, we sort, grind and sieve them. Second, we bind the particles into adhesive. Three biomaterials are based on three particle sizes of shell grains. The designed particles are bound with an adhesive powder that is produced from a pre-catalyzed urea-formaldehyde resin. Moreover, the water used is a non-polluting solvent. The biomaterials and two samples of Red and Beech Wood were immersed in water for 15 days, with mass measurements that were done on a daily basis. It was concluded that the swelling coefficient of the large distribution of biomaterial is smaller than the small distribution of biomaterial. However, Red and Beech Wood have the highest coefficient.
\end{abstract}

\section{INTRODUCTION}

In recent years, composite materials have attracted a lot of attention in various applications such as electronics, packaging, biomedical, and aerospace industries [1].

With an ever-growing environmental concern about the protection of all living things on earth and the requirements of legislative authorities to minimize the use of pollutants from petroleum resources, this has led scientists and engineers to pay more attention to the development of nature-based composites and to look for specific environmental protection and low-cost properties. Recently, the use of bio-composites has been highly valued and has attracted worldwide attention to replacing conventional composites filled with talc, glass, clay, or carbon, especially in the automotive industries, packaging, and construction [2].

Generally, bio-composites are produced by a combination of renewable, sustainable, and biodegradable matrices or feedstock, which are health and environment-friendly. They must be low density, inexpensive, non-toxic, and of non-oil origin while having good mechanical properties.

Morocco produces 128,000 tons of waste annually, its main interest lies in its fruit, consisting of two parts: almond with a percentage of $3 \%$ of the fruit and the rest in the form of residues. The hardness of the argan bark allows us to think about its use to produce new composite materials taking into account the new environmental constraints [3].

Composite materials offer new possibilities for manufacturers and designers to combine functions, shapes, and materials in increasingly efficient systems. These materials consist of a polymer matrix and reinforcing fibers, this is one of the goals of many researchers worldwide.

Taking into account the new environmental constraints, this study has as a principle to value the use of the argan hull in several fields of application $[4,5]$.

Obtained from renewable and biodegradable argan waste, which has a density base, low cost, and good mechanical properties [6-9].

Essabir et al. [7] studied the mechanical and thermal properties of composite materials of a polypropylene matrix $(\mathrm{C} 3 \mathrm{H} 6)_{\mathrm{n}}$ reinforced with argan particles. They used three different sizes of argan particles to mix with a polypropylene matrix, grafted with a linear block copolymer based on styrene and butadiene coupling agent, to improve adhesion between the particles and the matrix. Their thermal results show that the polypropylene-based argan particle composites are less thermally stable than the polypropylene matrix alone and that the decomposition temperature decreases with increasing particle size.

In another work, Bouqbis et al. [4] found another valuation of argan nut shells in the agricultural field. They used the biochar produced from argan nutshells, to improve the retention of water and nutrients in soils.

Laaziz et al. [10] have developed a new bio-composite based on polylactic acid reinforced with argan nutshells. They studied the effect of chemical surface treatments of argan on the morphological, mechanical, thermal, and rheological properties of polylactic acid. This made it possible to find 
possible solutions for problems related to bio-composites.

Another use in the field of batteries, Dahbi et al. [11] have developed a Na-Ion battery based on hard carbon synthesized via carbonization of the biomass of the argan shell, offering a capacity of more than $330 \mathrm{mAh} \mathrm{g}^{-1}$.

I recent work, Zbair et al. [12] used the shell of argan nuts as a precursor for the production of active charcoal. Two activated carbons $\mathrm{AC}-\mathrm{HP}$ and $\mathrm{AC}-\mathrm{Na}$ were prepared from the shell of argan nuts using a chemical activation method using phosphoric acid $\left(\mathrm{H}_{3} \mathrm{PO}_{4}\right)$ and sodium hydroxide $(\mathrm{NaOH})$ respectively. And they showed that using the argan shell is a sustainable approach to synthesize AC-HP, and it could be an ideal material for different applications (catalysis, environmental sanitation, and energy storage).

Boujibar et al. [13] manufactured an electrode using a simple activation technique; demonstrating an industryfriendly process, which is capable of having precise control over the pore size distribution of active charcoal derived from a natural resource. They used the argan shell in the construction of a high-performance electrode energy storage supercapacitor. This allowed a significant improvement in specific energy, with no or very negligible change in specific power.

Recently, Rahib et al. $[14,15]$ treated the burning characteristics of the argan shell in order to assess their potential for thermochemical conversion and to improve the understanding of the operational characteristics and the burning effect of biomass.

Our composite material consists of a reinforcement (Argan Shell) that ensures mechanical hold and a matrix (Urea Formaldehyde) that guarantees the structural cohesion and the forces transmission to the reinforcement

The advantage of Urea Formaldehyde adhesives is their initial solubility in water, hardness, non-flammability, good thermal properties, lack of color in the hardened, inexpensive. They are preferred for bonding plywood and other wood-based panels $[16,17]$.

Urea-formaldehyde resins are widely used adhesives in various fields of application including applied plywood, particleboard, medium-density optical fiberboards, oriented strand boards, and other artificial boards [18-21] due to their low cost, moderate drying temperature, the mechanical performance of bonds, and other advantages [22, 23]. This makes it possible to obtain materials with acceptable force values [24].

The objectives of the implementation of bio-compounds are not only to reduce the quantity of waste but also to recycle it by reusing it in several fields of application [6, 25-29].

In previous work "Bio-material from argan shells: Size effect on thermal conductivity" [30]. The thermal properties of argan-based composites bonded with urea-formaldehyde and water were studied. Three particle sizes (Nut-shells of Argan) were used with and without urea-formaldehyde to see the effect of the glue on the different grains of the argan tree. The results of the ranges with the glue have shown that the thermal conductivity decreases with the increase of the particle size, on the other hand, the diameter of the particles without glue increases with the increase of the thermal conductivity. Glue based on urea-formaldehyde helps to decrease thermal conductivity. The objective of this study is to measure over a period of time well determine the swelling rate of its different size distributions of argan glued with urea-formaldehyde and compare them to find the range that absorbs less water compared to others.

\section{MATERIALS AND METHODS}

\subsection{Procedure}

The almonds are sorted to extract the oil by different processes (roasting, grinding the almonds then mixing and pressing).

The argan shells recovered after extraction of the argan almonds are crushed by a hammer mill; this allows to obtain argan shells in the form of grains of different sizes, after sorting the dimensions using different sieves to select five dimensions of different diameters $(\mathrm{d})$.

Table 1 shows the composition of the three ranges (range 1 is small, range 2 is medium and range 3 is large) as a percentage of the different diameters of the argan core.

Table 1. Nut-shells of Argan particles distribution

\begin{tabular}{lccccc}
\hline & $\mathbf{0}<\mathbf{d}<\mathbf{0 . 5}$ & $\mathbf{0 . 5}<\mathbf{d}<\mathbf{1 . 0}$ & $\mathbf{1 . 0}<\mathbf{d}<\mathbf{1 . 7}$ & $\mathbf{1 . 7}<\mathbf{d}<\mathbf{2 . 5}$ & $\mathbf{2 . 5}<\mathbf{d}<\mathbf{3 . 7}$ \\
\hline $\begin{array}{l}\text { Range } \\
1(\text { R1) }\end{array}$ & $20 \%$ & $60 \%$ & $20 \%$ & - & - \\
$\begin{array}{l}\text { Range } \\
\text { 2(R2) }\end{array}$ & - & $20 \%$ & $60 \%$ & $20 \%$ & - \\
$\begin{array}{l}\text { Range } \\
\text { 3(R3) }\end{array}$ & - & - & $20 \%$ & $60 \%$ & $20 \%$ \\
\hline
\end{tabular}

Our bio-composite consists of 50\% of each homogenized range with $25 \%$ of urea-formaldehyde, and $25 \%$ of water as a solvent. This mixture is poured into a $(20 \times 20 \times 2) \mathrm{cm}^{3}$ mold and allowed to dry at room temperature of $25^{\circ} \mathrm{C}$ and at normal atmospheric pressure for 72 hours.

Then, using a band saw, each of these ranges was cut into cubic dimensions $(2 \times 2 \times 2) \mathrm{cm}^{3}$. Cutting is done in a way to eliminate the edge effect. We also cut a sample of redwood and another of beech wood, in cube $(2 \times 2 \times 2) \mathrm{cm}^{3}$.

\subsection{Swelling rate measurement}

The water absorption rate of our specimens was determined daily by immersing them in beakers filled with water for 15 days.

The absorption coefficient represents the ratio of the increase in the mass of the sample after immersion in water to the dry mass of the sample. The water absorption coefficient or the swelling coefficient $\mathrm{S}$ is defined by the following equation:

$$
S=\frac{m_{i}-m_{0}}{m_{0}}
$$

where, $\mathrm{m}_{0}$ is the sample mass before swelling, $\mathrm{m}_{\mathrm{i}}$ is the sample mass on the day (D).

\section{RESULTS AND DISCUSSION}

The results obtained are represented in the figures below, where the evolution of the swelling parameter was studied according to the days.

Figure 1 shows the swelling rate variation during 15 days, for the three ranges.

The results of this experiment have shown that the swelling rate of the range with large distributions absorbs less water than other ranges with small distributions (Figure 1). This is 
due to the specific surface of the range 3 which remains inferior to the other ranges 1 and 2 . The range size has a significant impact on the swelling rate.

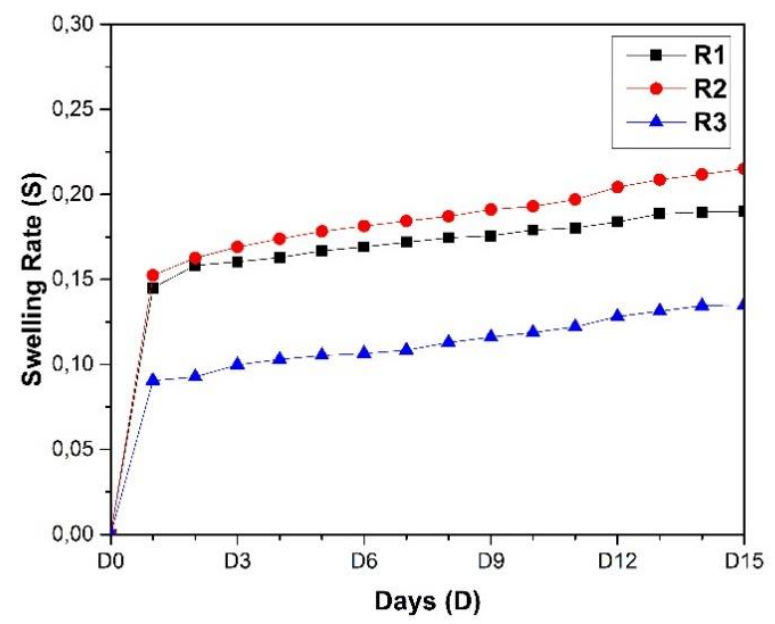

Figure 1. Swelling rate (S) according to the days for the three ranges

Figure 2 shows the swelling rate variation during 15 days from the R3 range, Red Wood (RW), and Beech Wood (BW).

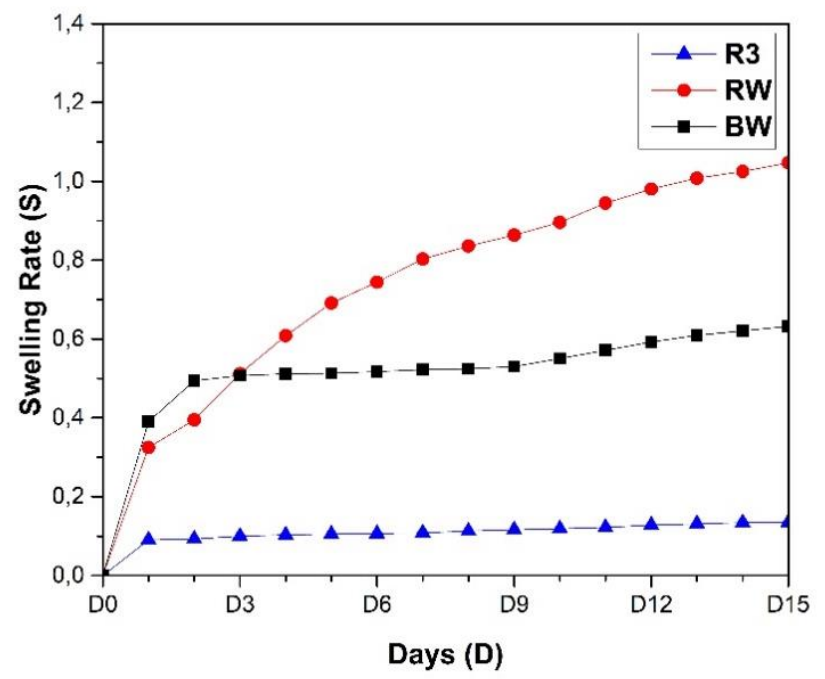

Figure 2. Swelling rate (S) as a function of days from the R3 range, Red Wood (RW) and Beech Wood (BW)

In the 2nd stage, we compared the 3rd range composed of large particles with redwood and beech wood (Figure 2), the obtained results show that the swelling rate of BW and R3 increase rapidly with days (from day 1 to 2 ), then it is steady between days 3 and 15. However, the increase of the days leads to the increased swelling rate of RW. Hence, the third range absorbs practically nothing compared to these two kinds of wood this range absorbs practically nothing compared to these two kinds of wood.

\section{CONCLUSIONS}

The valorization of this shell of argan nuts is to develop new biomaterials that have properties that meet environmental requirements in terms of environmental pollution reduction, waste disposal, and recycling. This valuation also improves the financial situation of the people of the region. We conducted an experimental study to determine the swelling behavior of our material in the presence of water. It was concluded that the range formed by large particles inflates less than that formed by small particles. This is due to the specific surface of the range 3 which remains above the ranges 1 and 2. We found that the third range absorbs less water than redwood and beech wood. This may be due to the increasing compactness as the mixing dimensions of argan particles decrease. The use of composite wood is promising in wetlands.

\section{ACKNOWLEDGMENT}

"Higher Institute of Maritime Studies - Casablanca", supported this work. We are pleased to acknowledge it. The authors thank also A. Elbouari from the Laboratory of Physical Chemistry of Applied Materials, Faculty of Sciences Ben M'Sik, Hassan II University of Casablanca, Morocco, for his technical support during the production of data.

\section{REFERENCES}

[1] Keya, K.N., Kona, N.A., Koly, F.A., Maraz, K.M., Islam, M.N., Khan, R.A. (2019). Natural fiber reinforced polymer composites: History, types, advantages and applications. Materials Engineering Research, 1(2): 6985. https://doi.org/10.25082/MER.2019.02.006

[2] Owusu, P.A., Asumadu-Sarkodie, S. (2016). A review of renewable energy sources, sustainability issues and climate change mitigation. Cogent Engineering, 3(1): 1167990 . https://doi.org/10.1080/23311916.2016.1167990

[3] M'Hirit, O., Benzyane, M., Benchekroum, F., El Yousfi, S.M., Bendaanoun, M. (1998). L'arganier: une espèce forestière à usages multiples. Ed. Mardaga, Sprimont, Belgique. ISBN 2870096844

[4] Bouqbis, L., Daoud, S., Koyro, H.W., Kammann, C.I., Ainlhout, L.F.Z., Harrouni, M.C. (2016). Biochar from argan shells: production and characterization. International Journal of Recycling of Organic Waste in Agriculture, 5(4): 361-365. https://doi.org/10.1007/s40093-016-0146-2

[5] El Boundati, Y., Ziat, K., Naji, A., Saidi, M. (2019). Generalized fractal-like adsorption kinetic models: Application to adsorption of copper on Argan nut shell. Journal of Molecular Liquids, 276: 15-26. https://doi.org/10.1016/j.molliq.2018.11.121

[6] Nekhlaoui, S., Essabir, H., Kunal, D., Sonakshi, M., Bensalah, M. O., Bouhfid, R., Qaiss, A. (2015). Comparative study for the talc and two kinds of Moroccan clay as reinforcements in polypropyleneSEBS-g-MA matrix. Polymer Composites, 36(4): 675684. https://doi.org/10.1002/pc.22986

[7] Essabir, H., Hilali, E., Elgharad, A., El Minor, H., Imad, A., Elamraoui, A., Al Gaoudi, O. (2013). Mechanical and thermal properties of bio-composites based on polypropylene reinforced with Nut-shells of Argan particles. Materials \& Design, 49: 442-448. https://doi.org/10.1016/j.matdes.2013.01.025

[8] Essabir, H., Bensalah, M.O., Rodrigue, D., Bouhfid, R. (2016). Biocomposites based on Argan nut shell and a polymer matrix: Effect of filler content and coupling 
agent. Carbohydrate Polymers, 143: 70-83. https://doi.org/10.1016/j.carbpol.2016.02.002

[9] Yang, Z., McElrath, K., Bahr, J., D’Souza, N.A. (2012). Effect of matrix glass transition on reinforcement efficiency of epoxy-matrix composites with single walled carbon nanotubes, multi-walled carbon nanotubes, carbon nanofibers and graphite. Composites Part B: Engineering, 43(4): 2079-2086. https://doi.org/10.1016/j.compositesb.2012.01.049

[10] Laaziz, S.A., Raji, M., Hilali, E., Essabir, H., Rodrigue, D., Bouhfid, R. (2017). Bio-composites based on polylactic acid and argan nut shell: Production and properties. International Journal of Biological Macromolecules, 104: 30-42. https://doi.org/10.1016/j.ijbiomac.2017.05.184

[11] Dahbi, M., Kiso, M., Kubota, K., Horiba, T., Chafik, T., Hida, K., Matsuyamad, T., Komaba, S. (2017). Synthesis of hard carbon from argan shells for Na-ion batteries. Journal of Materials Chemistry A, 5(20): 9917-9928. https://doi.org/10.1039/C7TA01394A

[12] Zbair, M., Ainassaari, K., Drif, A., Ojala, S., Bottlinger, M., Pirilä, M., Bensitel, M., Brahmi, R. (2018). Toward new benchmark adsorbents: preparation and characterization of activated carbon from argan nut shell for bisphenol A removal. Environmental Science and Pollution Research, 25(2): 1869-1882. https://doi.org/10.1007/s11356-017-0634-6

[13] Boujibar, O., Ghosh, A., Achak, O., Chafik, T., Ghamouss, F. (2019). A high energy storage supercapacitor based on nanoporous activated carbon electrode made from Argan shells with excellent ion transport in aqueous and non-aqueous electrolytes. Journal of Energy Storage, 26: 100958. https://doi.org/10.1016/j.est.2019.100958

[14] Rahib, Y., Sarh, B., Bostyn, S., Bonnamy, S., Boushaki, T., Chaoufi, J. (2020). Non-isothermal kinetic analysis of the combustion of argan shell biomass. Materials Today: Proceedings, 24: 11-16. https://doi.org/10.1016/j.matpr.2019.07.437

[15] Rahib, Y., Boushaki, T., Sarh, B., Chaoufi, J. (2021). Combustion and pollutant emission characteristics of argan nut shell (ANS) biomass. Fuel Processing Technology, 213: 106665. https://doi.org/10.1016/j.fuproc.2020.106665

[16] Pizzi, A. (1983) Wood Adhesives Chemistry and Technology. Marcel Dekker, New York. https://doi.org/10.4236/ojpchem.2017.72002

[17] Gadhave, R.V., Mahanwar, P.A., Gadekar, P.T. (2017). Starch-based adhesives for wood/wood composite bonding: Review. Open Journal of Polymer Chemistry, $7(2)$ :

$19-32$ https://doi.org/10.4236/ojpchem.2017.72002

[18] Hematabadi, H., Behrooz, R., Shakibi, A., Arabi, M. (2012). The reduction of indoor air formaldehyde from wood based composites using urea treatment for building materials. Construction and Building Materials, 28(1): 743-746.

https://doi.org/10.1016/j.conbuildmat.2011.09.018

[19] Chen, S., Lu, X., Wang, T., Zhang, Z. (2016). Preparation and characterization of urea-formaldehyde resin/reactive kaolinite composites. Particuology, 24:
203-209. https://doi.org/10.1016/j.partic.2015.05.007

[20] Liu, Y., Ye, L., Shu, Y., Zhao, X. (2018). In situ preparation of intrinsic flame retardant urea formaldehyde/aramid fiber composite foam: Structure, property and reinforcing mechanism. Composites Part A: Applied Science and Manufacturing, 115: 274-282. https://doi.org/10.1016/j.compositesa.2018.10.015

[21] Neuser, S., Manfredi, E., Michaud, V. (2014). Characterization of solvent-filled polyurethane/ureaformaldehyde core-shell composites. Materials Chemistry and Physics, 143(3): 1018-1025. https://doi.org/10.1016/j.matchemphys.2013.10.041

[22] Ferra, J.M., Ohlmeyer, M., Mendes, A.M., Costa, M.R. N., Carvalho, L.H., Magalhães, F.D. (2011). Evaluation of urea-formaldehyde adhesives performance by recently developed mechanical tests. International Journal of Adhesion and Adhesives, 31(3): 127-134. https://doi.org/10.1016/j.ijadhadh.2010.11.013

[23] Akyüz, K.C., Nemli, G., Baharoğlu, M., Zekoviç, E. (2010). Effects of acidity of the particles and amount of hardener on the physical and mechanical properties of particleboard composite bonded with urea formaldehyde. International Journal of Adhesion and Adhesives, 30(3): 166-169. https://doi.org/10.1016/j.ijadhadh.2009.12.006

[24] Sajeeb, A.M., Babu, C.S., Arif, M.M. (2018). Evaluation of mechanical properties of natural fiber reinforced melamine urea formaldehyde (MUF) resin composites. Materials Today: Proceedings, 5(2): 6764-6769. https://doi.org/10.1016/j.matpr.2017.11.335

[25] Neuser, S., Manfredi, E., Michaud, V. (2014). Characterization of solvent-filled polyurethane/ureaformaldehyde core-shell composites. Materials Chemistry and Physics, 143(3): 1018-1025. https://doi.org/10.1016/j.matchemphys.2013.10.041

[26] Duan, H., Jiang, Z., Zhu, S., Yao, P., Sun, Q. (2012). New composite grouting materials: Modified ureaformaldehyde resin with cement. International Journal of Mining Science and Technology, 22(2): 195-200. https://doi.org/10.1016/j.ijmst.2011.08.009

[27] Hazarika, A., Deka, B.K., Maji, T.K. (2015). Melamineformaldehyde acrylamide and gum polymer impregnated wood polymer nanocomposite. Journal of Bionic Engineering, 12(2): 304-315. https://doi.org/10.1016/S1672-6529(14)60123-2

[28] Naveen, J., Jawaid, M., Amuthakkannan, P., Chandrasekar, M. (2019). Mechanical and physical properties of sisal and hybrid sisal fiber-reinforced polymer composites. In Mechanical and Physical Testing of Biocomposites, Fibre-Reinforced Composites and Hybrid Composites, 2019: 427-440. https://doi.org/10.1016/B978-0-08-102292-4.00021-7

[29] Madhoushi, M., Chavooshi, A., Ashori, A., Ansell, M.P., Shakeri, A. (2014). Properties of wood plastic composite panels made from waste sanding dusts and nanoclay. Journal of Composite Materials, 48(14): 1661-1669. https://doi.org/10.1177/0021998313489899

[30] Babty, F., Derouiche, A., Bettachy, A., Mordane, S., Fassi, S. E., Elbouari, A., Sair, S. (2019). Biomaterial from argan shells: Size effect on thermal conductivity. In AIP Conference Proceedings, 2109(1): 070002. https://doi.org/10.1063/1.5110126 